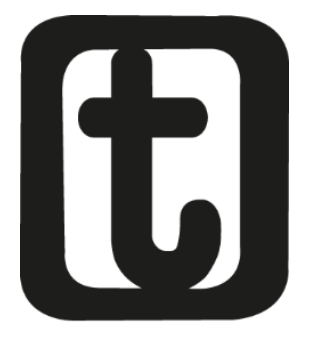

ARTIGOS TEMÁTICOS/

THEMATIC ARTICLES

\title{
POLÍTICAS ECONÔMICAS E SOCIAIS NA AMÉRICA LATINA
}

Social and economic policies of Latina American countries

\section{Luiz Jorge V. Pessoa de Mendonça ${ }^{1}$}

\section{RESUMO}

As avaliações das políticas públicas latino-americanas aparecem como positivas tanto para setores da esquerda quanto para os adeptos da ortodoxia liberal. Para os primeiros, as novas políticas em benefício das classes mais desfavorecidas representam um primeiro passo em direção a mudanças mais profundas. Para os segundos, as políticas monetárias e fiscais ortodoxas e a melhor inserção no comércio internacional fornecem as bases para um crescimento sustentável. No entanto, quando avaliamos as políticas sociais atuais, cuja base é o conceito de vulnerabilidade social, fica claro que a superexploração da força de trabalho e a expropriação de amplas parcelas das populações envolvidas continuam sem solução. $O$ principal mérito dessas políticas parece ser, em alguns casos, contribuir para a construção de um modelo econômico alternativo ao atual.

\footnotetext{
1 Professor Doutor do Departamento de Economia e do Programa de PósGraduação em Política Social da Universidade Federal do Espírito Santo. E-mail: <ljvpmendonca@gmail.com>.
} 


\section{tempordils}

MENDONÇA, L. J. V. P. de. POLÍTICAS ECONÔMICAS E SOCIAIS

\section{PALAVRAS-CHAVE}

Desigualdade e vulnerabilidade social. Política social e econômica. Neoliberalismo na América Latina.

\section{ABSTRACT}

The economic and social policies in Latin America countries are considered as a positive way by left economists and liberal ones. On the one hand, one believes that the control of fiscal and monetary policies were necessary to deliver sustainable economic growth. This would be the first condition to reduce both poverty and inequality. On the other hand, one believes that politics towards the poorest population would be sufficient to create conditions for important political and social improvements in Latin America countries. Nevertheless, when we consider the concept of social vulnerability and the aims of economic policy, it seems that over exploitation of work force continues to be unsolved

\section{KEYWORDS}

Inequality and social policies. Social vulnerability and public policies. Neoliberalism in Latin America.

\section{INTRODUÇÃO}

As perspectivas para o século $\mathrm{XXI}$ em relação aos países que compõem a América Latina aparecem, paradoxalmente, numa primeira avaliação, como positivas tanto para aqueles que compartilham uma visão mais à esquerda quanto para aqueles alinhados com a direita. Por um lado, a elaboração e a aplicação de políticas sociais para o enfrentamento da pobreza assumem uma relevância sem precedentes na história. Tratar-se-ia, então, de um resgate social do principal e secular problema latino-americano, a saber: a desigualdade social. A solução deste problema permitiria um 


\section{temporalis}

\section{MENDONÇA, L. J. V. P. de. POLÍTICAS ECONÔMICAS E SOCIAIS}

crescimento econômico mais equânime, ancorado no potencial interno das sociedades latino-americanas e de acordo com as reais necessidades e possibilidades de seus povos. Por outro lado, as políticas econômicas variam em diferentes graus entre a aplicação da ortodoxia econômica até a tentativa de criar alternativas ao neoliberalismo, consolidado a partir do Consenso de Washington e amplamente aplicado na década de noventa como forma de enfrentar a crise da década anterior.

Não há uma correspondência direta entre a evolução econômica e os resultados observados no campo social. Em alguns casos, a dinâmica política e os avanços sociais contrapõem-se aos princípios da ortodoxia econômica liberal adotada, constituindo-se, assim, um foco de resistências tanto das massas populares quanto dos governantes mais progressistas. Em outros casos, apesar da sociedade aparentar avanços políticos, há apenas uma nova roupagem da velha dinâmica do capitalismo dependente e excludente que caracteriza a América Latina.

Além disso, é importante frisar que a evolução mais recente das condições de vida da maior parte dos povos latinos não se reproduziu igualmente nos diferentes países, seja em termos de avanço do socialliberalismo, como forma de gerenciar a expropriação/exclusão social, seja em termos de resistência ou de desenvolvimento de alternativas às políticas neoliberais. Os avanços e recuos foram diferenciados não só por conta dos aspectos políticos dos sucessivos governos, mas principalmente por conta do desenvolvimento e principalmente das possibilidades específicas de resistência de cada sociedade. A hipótese é a de que o grau diferenciado de centralização, de universalização, de institucionalização e de experiência acumulada nas políticas sociais em cada um dos países determinou o grau de substituição da lógica de solidariedade pela lógica individualista (MARQUES, 2000, p. 144). 


\section{temporolis}

MENDONÇA, L. J. V. P. de. POLÍTICAS ECONÔMICAS E SOCIAIS

\section{A INTERFACE ATUAL ENTRE POLÍTICA ECONÔMICA E POLÍTICAS SOCIAIS FOCALIZADAS E ASSISTENCIAIS}

Para os neoliberais, os países latino-americanos têm condições de colher os frutos das políticas econômicas ortodoxas responsáveis pelas mudanças mais recentes. A melhor inserção no comércio exterior, a partir da modernização da base produtiva e da liberalização comercial voltadas à exportação, em especial a exploração de matérias-primas e produtos da agroindústria, é base da argumentação desta corrente. Além disso, é necessário que o aprimoramento das políticas econômicas neste campo esteja de acordo com a manutenção de políticas fiscais e monetárias que assegurem o controle dos gastos públicos e impliquem altas taxas de juros que beneficiam, por sua vez, o capital financeiro.

Por um lado, uma reforma fiscal passa à ordem do dia, porém no sentido de promover o desmonte de direitos históricos adquiridos pelos trabalhadores, a desoneração fiscal em benefício dos empresários e o maior apoio às atividades de valorização do capital. Este é o caso, por exemplo, dos incentivos financeiros e legais para a criação e o desenvolvimento dos fundos de previdência privada em lugar da ampliação do sistema de previdência e assistência pública, das isenções/diminuição de impostos que incidem sobre as empresas e da concessão/ampliação da participação de empresas em diversos campos de atuação do Estado.

Por outro lado, a política monetária de cunho ortodoxo coloca o comando do processo de reprodução do capital sob o domínio incontestável do capital financeiro. As altas taxas de juros impõem frequentemente uma reestruturação do capital produtivo, nem sempre com sucesso assegurado e com efeitos deletérios sobre o mundo do trabalho. Do mesmo modo, as oscilações do câmbio 


\section{temporalis}

\section{MENDONÇA, L. J. V. P. de. POLÍTICAS ECONÔMICAS E SOCIAIS}

resultantes da liberalização da conta capital acarretam consequências drásticas e repentinas em diversos setores produtivos, permitindo que o nível de emprego e de renda oscile bruscamente. A adoção do regime de taxas de câmbio flutuantes implica oscilações repentinas no câmbio resultante de movimentos especulativos, o que termina por comprometer a liberdade das autoridades monetárias. Desse modo, as políticas monetárias e fiscais não têm mais a mesma eficácia para a promoção da industrialização e para a diversificação da base produtiva, com consequente geração de emprego. Tal fator ainda é agravado em escala sem precedentes na história quando consideramos que a maior parte dos recursos financeiros tem caráter especulativo e de curto prazo. É isso que explica porque a conta capital e financeira corresponde ao principal suporte da propalada saúde econômica dos países latinos, em especial a rubrica financeira ${ }^{2}$, e isto mesmo que a evolução dos níveis de emprego, de renda e a deterioração do perfil distributivo estejam bem aquém do mínimo desejável.

Nesse ponto, surge uma espécie de social-liberalismo, isto é, um conjunto de preocupações com a questão social, porém, sem comprometer os ditames da ortodoxia monetarista como exposto acima. Os problemas sociais têm de ser resolvidos por outra esfera que não a econômica. Considera-se que o mercado tem suas próprias leis e as políticas econômicas devem criar as condições para que se desenvolvam livremente. As políticas sociais, por sua vez, tornam-se descentralizadas e totalmente direcionadas para segmentos específicos da sociedade. Elas são consideradas

\footnotetext{
2 Em 2008, segundo o relatório anual do Banco Central de 2008, o déficit do Brasil em transações correntes foi de US\$28,3 bilhões, enquanto o resultado da conta capital e financeira foi de superávit de US\$ 33,0 bilhões. A conta financeira contribuiu com US\$32,0 bilhões para esse resultado (sendo a maior parte devido ao IDE, da ordem de US\$24,6 bilhões) e a conta capital contribui apenas com US\$1,1 bilhão.
} 


\section{tempordils}

MENDONÇA, L. J. V. P. de. POLÍTICAS ECONÔMICAS E SOCIAIS

relevantes na medida em que possam assegurar que o mercado de trabalho não constitua uma restrição ao crescimento econômico: falta de mão-de-obra qualificada ou exigências trabalhistas que comprimam os lucros.

Mesmo na visão neoestruturalista da $\mathrm{CEPAL}^{3}$, não há uma alteração na essência da intervenção do Estado no mercado. Ela limita-se ao reconhecimento da relevância que os governos podem ter para instalação e desenvolvimento de novos empreendimentos ao fomentar um ambiente com boas expectativas de crescimento. Os grupos econômicos ou classes sociais não constituem mais categorias relevantes para a intervenção direta, tal a multiplicidade de situações. O Estado não é mais um provedor exclusivo das necessidades dos grupos sociais, qualquer que seja o bem ou direito em questão. No entanto, ele pode e deve prover a condições institucionais e legais para que o mercado atenda às demandas dos inúmeros grupos sociais.

Assim, conceitualmente dissemina-se o princípio de vulnerabilidade como aquele mais adequado à compreensão e atuação sobre os problemas sócioeconômicos dos diversos países. Não se vê mais a pobreza extrema nestes países como contrapartida/resultado do capitalismo dependente, sequer como característica estrutural na formação das sociedades latinas ${ }^{4}$. Defende-se 0 conceito de vulnerabilidade social como mais adequado para nortear as políticas sociais na medida em que define a população-alvo a partir de mais elementos do que a renda monetária. Por um lado, para esta corrente é inegável que um determinado grupo pode a

3 Sobre o desenvolvimento das teorias cepalinas na era da globalização, consultar Kay (2009).

${ }^{4}$ A questão passa a ser tratada como decorrente da existência de novos atores, com novos papéis na sociedade (mulheres indígenas, idosos etc.). Uma discussão mais aprofundada encontra-se em Prado (2003). 


\section{temporalis}

\section{MENDONÇA, L. J. V. P. de. POLÍTICAS ECONÔMICAS E SOCIAIS}

qualquer momento perder seu vínculo com a atividade que vinha exercendo, seja pela precariedade na forma contratual do emprego, seja pela natureza da atividade exercida - em geral, marginal às atividades responsáveis pela dinâmica econômica da região em questão. Por outro lado, também não se pode deixar de lado o fato de que os indivíduos dos extratos sociais mais frágeis têm outros meios de sobrevivência e inserção no sistema econômico.

O conceito de vulnerabilidade inclui também as condições materiais e os laços sociais individuais como elemento importante para a ação do poder público. As relações familiares e sociais, bem como a posse ou acesso a certos bens e o próprio conjunto de valores e percepções subjetivas que guiam o esforço produtivo individual são elementos importantes para definir a condição dos vulneráveis. Esses outros aspectos devem ser vistos como uma riqueza não comensurável, porém capazes de criar as condições para que o pobre construa sua própria alternativa. "Por isso que alguns dos especialistas do Banco Mundial enfatizam que os pobres devem ser vistos como 'administradores estratégicos' de um portfólio complexo de ativos" (PIZARRO, 2001, p. 12). A política social passa a ser a de auxiliar a gestão do portfólio que cada cidadão ou grupo possui, e este portfólio não pode ser limitado ao nível de pobreza ou renda. As redes sociais de cada indivíduo e a vocação específica de cada grupo social têm de ser consideradas na distribuição dos benefícios governamentais. Os programas sociais passam a ter a função de incentivar os próprios indivíduos a criarem suas alternativas. As políticas de qualificação de mão-deobra com base na teoria do capital humano, a da geração de renda a partir do incentivo às iniciativas locais ou do melhor aproveitamento dos recursos disponíveis nos setores informais e a contínua necessidade de reformulação das ações sociais para se adequarem às novas realidades são bons exemplos disso. É nesse 


\section{tempordils}

MENDONÇA, L. J. V. P. de. POLÍTICAS ECONÔMICAS E SOCIAIS

sentido que as políticas sociais recomendadas pelos organismos internacionais são ditas descentralizadas, focalizadas e assistencialistas.

Desse modo, as políticas sociais atuais se apresentam, novamente apenas em termos de discurso político, como uma mudança de prioridade frente ao passado recente e em benefício dos mais pobres. Nesse movimento, os governos ditos de centro-esquerda se legitimam mantendo políticas econômicas determinadas pelas agências e organismos financeiros internacionais, privados e públicos, ao mesmo tempo em que contêm os avanços das lutas sociais, por vezes sendo forte instrumento para o desmonte de conquistas já consolidadas pelos trabalhadores. As políticas sociais de proteção não se direcionam mais, como no passado, ao conjunto da classe trabalhadora (empregados e desempregados), limitando-se a segmentos determinados em termos de renda, região e condições sociais. Um bom exemplo é o caso brasileiro, em que o próprio Ministério do trabalho adota esses princípios para pautar seus programas de atuação (BRASIL, 2007). As políticas sociais ganham então apenas o atributo de políticas pontuais, ou seja, individualizadas segundo a especificidade do grupo em questão.

O que efetivamente é consequência perversa da acumulação capitalista - o emprego precário, o desemprego e a marginalização social - é visto como uma característica natural, que não deve ser tratada de forma a prejudicar as necessidades da acumulação capitalista. O aumento vertiginoso do emprego informal e de extratos sociais marginalizados passa a ser considerado como algo anacrônico ao próprio sistema econômico e não como resultado inevitável do padrão de acumulação à dominância financeira. Pior ainda, ao pautarem as políticas econômicas e sociais por tais parâmetros, a noção de cidadão passa a ser definida pelo critério 


\title{
temporalis
}

MENDONÇA, L. J. V. P. de. POLÍTICAS ECONÔMICAS E SOCIAIS

de fracasso social, descartando-se as políticas universais, de redistribuição de renda e a plenitude dos direitos sociais do próprio público alvo dessas políticas. É por isso que tais políticas são também denominadas como focalizadas.

Não se pode negar que tais políticas apresentam bons resultados quando observadas as estatísticas nos diversos países. Porém, também é claro o caráter precário e residual dessa melhoria: se a pobreza e a indigência diminuíram nos países latinos quando avaliados à luz das políticas sociais focalizadas, tal resultado não gerou uma dinâmica própria, de modo que os beneficiados pudessem prescindir dos recursos a eles alocados. Em outras palavras: não se constrói um modelo de desenvolvimento futuro com melhor distribuição de renda e direitos sociais consolidados para a maioria. Um bom exemplo é a evolução observada após a crise de 2008, quando houve desaceleração na redução da pobreza e aumento da indigência:

\begin{abstract}
A diminuição da taxa de pobreza em 2008, em relação a 2007 , de 1,1 ponto percentual, é notavelmente inferior à redução da pobreza que se produziu entre 2002 e 2007, de 2 pontos percentuais por ano. Por sua vez, nos mesmos períodos de referência mencionados, a taxa de indigência cresceu 0,3 ponto percentual, depois de ter diminuído a um ritmo de $1,4 \%$ por ano (CEPAL, 2009, p. 9).
\end{abstract}

Se os resultados positivos são significativos apenas quando a economia está em crescimento, podemos inferir que os resultados de tais políticas não são efetivos se pensarmos em modelo de crescimento sustentável e baseado em melhor distribuição de renda. De fato, o sucesso dos diversos programas é relativo, pois não chegam a criar condições para que os resultados se mantenham. A desaceleração no ritmo de diminuição da pobreza a 


\section{temporalis}

MENDONÇA, L. J. V. P. de. POLÍTICAS ECONÔMICAS E SOCIAIS

partir de determinado ponto significa que as alocações dos recursos para os diversos segmentos da população não têm efeitos duradouros e não criam qualquer dinâmica própria relevante. Desse modo, essas políticas também podem, além de pontuais e focalizadas, ser consideradas como políticas assistenciais.

Portanto, em termos econômicos parece haver outra explicação para a continuidade e insistência na manutenção e no aprofundamento das políticas atuais.

\section{A EXPROPRIAÇÃO E A POLÍTICA ECONÔMICA NO CAPITALISMO DEPENDENTE}

Uma característica fundamental do modo de produção capitalista é o grau de exploração do capital sobre a força de trabalho, produção e apropriação da mais-valia, que permitirá maior ou menor lucro segundo as condições de mercado e de acordo com a proporção de capital empregado. O lucro e o ritmo de acumulação de capital dependem do grau de exploração da mão-de-obra, dada as condições de mercado, as condições técnicas de produção e a composição orgânica do capital.

Outro aspecto indissociável da própria essência do modo de produção capitalista é a expropriação contínua da força de trabalho. Isto é, além da expropriação inicial, historicamente necessária para que o capitalismo surja e se desenvolva, há ainda a expropriação que se reproduz em escala ampliada ao longo do processo de produção capitalista. Isto é, a análise sobre a acumulação primitiva e a expropriação vai mais longe do que o período histórico tratado: “Marx não para por aí e, no mesmo parágrafo, afirma que a expropriação não se limita a esse primeiro momento, pois nela repousa a base social da dominação capitalista" (FONTES, [200 -?], p. 5). 


\section{tempordilis}

\section{MENDONÇA, L. J. V. P. de. POLÍTICAS ECONÔMICAS E SOCIAIS}

Em termos gerais, os efeitos perversos da acumulação sobre a população incluem diversas formas de expropriação: as que incidem sobre os pequenos proprietários, as que incidem sobre os próprios capitalistas (concentração de capital) e as que incidem sobre os trabalhadores. Como resultado final, trata-se não só do aumento do número da classe trabalhadora, mas também da fragilização decorrente da deterioração na correlação de forças contra o capital. Em outros termos, no mundo do trabalho, há degradação das condições de vida, a persistência e o aumento das condições de penúria e fome ${ }^{5}$.

A particularidade no caso latino é que a perda de renda, devido à deterioração dos termos de troca no comércio internacional e ao fluxo financeiro em benefício dos países centrais, agrava o histórico problema da desigualdade econômica e social que caracteriza a América Latina. Além disso, o ajuste preconizado e aplicado segundo os preceitos do Consenso de Washington não permite a resolução do problema. Seja pelo aumento das remessas de lucros, seja pelo pagamento de juros, potencializado pela volatilidade/liberdade do capital financeiro internacional, o resultado final é que tal sangria de recursos é compensada pelo aumento da exploração da força de trabalho. Enquanto as elites continuam sem sofrer perda no seu nível de renda e o processo de acumulação interna assegura os recursos para sua continuidade, a desigualdade econômica e social perdura indefinidamente, embora

\footnotetext{
${ }^{5}$ A esse respeito é elucidativo o seguinte trecho de Marx: “[...] uma vez que o número dos capitalistas diminuiu, a sua competição por trabalhadores dificilmente continua a existir, enquanto a competição entre trabalhadores, devido ao aumento do seu número, se tornou maior, mais anormal e mais violenta [...], o resultado inevitável para o trabalhador é o trabalho excessivo e a morte prematura, a degradação em máquina, a sujeição ao capital que se acumula em ameaçadora oposição a ele, nova concorrência, a morte à fome ou a mendicidade para uma parte dos trabalhadores (MARX, [1932]1989, p.106)".
} 


\section{tempordils}

MENDONÇA, L. J. V. P. de. POLÍTICAS ECONÔMICAS E SOCIAIS

com ações e programas pontuais. Em outras palavras, mantém-se sobre nova roupagem o "[...] desenvolvimento do subdesenvolvimento [...]", tal qual explicitado pela Teoria da dependência. "Em consequência, os programas direcionados à pobreza configuram uma dimensão estratégica que procura administrar expressões específicas da questão social, incorporando, de forma parcial e restrita, demandas sociais" (SILVA, 2007, p. 5).

As experiências recentes de políticas sociais nos países latinoamericanos devem, portanto, ser avaliadas tendo em vista esses dois pólos de interpretação. Alguns casos correspondem de fato à adoção dos princípios do social-liberalismo, de modo que se continua seguindo a orientação do Banco Mundial e demais instituições internacionais, naturalizando a pobreza e a desigualdade social e viabilizando a continuidade das políticas econômicas ortodoxas. Em outros casos, a própria dinâmica política e social coloca-se como resistência ao aumento e permanência da expropriação, forma de avanço/modernização das relações capitalistas de produção. Mais do que uma simples classificação teórica de cada caso específico, de um país qualquer ou de determinado movimento social, trata-se de avaliar em que medida a dinâmica política subsequente constrói alternativas econômicas ou contribui para a consolidação da desigualdade social em uma estrutura econômica modernizada.

Desse modo, mais do que avaliar a trajetória dos diversos casos, pretendemos demonstrar no item seguinte que se o embate capital versus trabalho determina a configuração e a extensão das políticas sociais, isto não significa por si só que a existência e até mesmo a extensão dos programas sociais possam ser considerados um avanço na construção de uma alternativa ao modelo capitalista de exploração. Na maioria dos casos, podemos inferir que tal 


\section{temporalis}

MENDONÇA, L. J. V. P. de. POLÍTICAS ECONÔMICAS E SOCIAIS

resultado é decorrência da fragilidade do trabalho e sua espoliação pelo capital, tanto maior quanto maior for a dependência/subserviência ao modelo de inserção na economia mundial com base nas relações de mercado capitalista. Em termos de políticas sociais, a contrapartida constitui-se justamente na inserção de amplas camadas da população tendo como base uma hipotética inserção no sistema via mercado. Porém, em outros casos, a eclosão de novos movimentos sociais e a persistência das reivindicações por parte dos já existentes, apesar das iniciativas políticas de cooptação desses movimentos por governos populistas comprovam a expropriação contínua da força de trabalho.

\section{CONSIDERAÇÕES SOBRE ALGUMAS EXPERIÊNCIAS RECENTES EM PAÍSES LATINOS}

Em termos de evolução de alguns aspectos da política econômica, podemos classificar os países em três grupos principais ${ }^{6}$. O primeiro correspondente aos países do Cone Sul, o segundo pela Colômbia, México e países da América central e Caribe e o terceiro pela Venezuela e Bolívia. É importante observar que, embora estilizada, tal classificação permite realçar as principais estratégias e políticas econômicas em curso. Em linhas gerais, os países do primeiro grupo correspondem a uma tentativa de desenvolvimento nos padrões impostos pelo capital globalizado. Eles possuem como elemento inovador o fato de questionarem, em graus diferenciados, a dependência em relação aos EUA e de terem as políticas sociais como importante elemento de legitimação. O segundo grupo procura políticas econômicas cujo principal objetivo é o de alinhar suas economias às novas exigências do

\footnotetext{
${ }^{6}$ A respeito da distinção mais detalhada das políticas econômicas que orientam as experiências dos diversos países consultar Carvalho (2008).
} 


\section{tempordils}

MENDONÇA, L. J. V. P. de. POLÍTICAS ECONÔMICAS E SOCIAIS

capital globalizado e à dominância financeira, tendo como principal estratégia econômica adotar medidas necessárias para a implementação das exigências atuais do livre mercado, institucionalizado através dos acordos bilaterais de livre comércio com os Estados Unidos. Os casos venezuelano e boliviano constituem uma tentativa concreta de construção de uma alternativa. No entanto, em ambos os países não houve alteração da base econômica anterior à medida que os interesses das elites exportadoras continuam salvaguardados.

No Cone Sul, as políticas econômicas ganham coloração mais independente, embora ainda obedeçam a certos limites que impedem uma verdadeira mudança. Por exemplo, na Argentina, as iniciativas do governo Kirchner de priorizar a integração regional consolidando um modelo mais baseado na integração produtiva do que no intercâmbio comercial, como vinha sendo feito ao longo dos anos noventa - é digna de mérito. O mesmo pode-se dizer de sua atuação ao rechaçar a excessiva ingerência do FMI na gestão econômica pós-crise de 2001. Não restam dúvidas de que as políticas salariais e o aprofundamento dos planos sociais do governo Duhalde foram importantes para a retomada do crescimento econômico ${ }^{7}$. No entanto, em termos políticos, essas iniciativas tiveram mais o papel de reforçar o assistencialismo do que potencializar a luta contra o aumento da exploração e precarização do trabalho. As políticas sociais do governo Kirchner acabaram não contribuindo para a construção de alternativas econômicas, a despeito de alguns avanços políticos. Podemos dizer que a cooptação política pelo governo justicialista não foi suficiente para desmobilizar os trabalhadores desempregados. A

7 O Mecanismo de Adaptação Competitiva, bem como a atuação de conciliação do governo argentino em importantes contenciosos mais recentes com o Brasil demonstram essa opção para o formato procurado de integração pelo Mercosul. Para maiores detalhes ver Stuart (2008). 


\title{
temporalis
}

\section{MENDONÇA, L. J. V. P. de. POLÍTICAS ECONÔMICAS E SOCIAIS}

própria persistência na atuação desses movimentos demonstra que a expropriação da força de trabalho prevalece sobre o avanço e as benesses das políticas sociais. E esses avanços se devem principalmente à iniciativa das classes operárias:

\begin{abstract}
Enquanto a política governamental apresentava a tendência de mascarar a exclusão, graças à política de assistência, ao controle social e à diabolização do movimento dos piqueteros, as fronteiras da precariedade começaram a se mostrar mais flexíveis, favorizando uma atividade maior de trabalhadores precarizados, assim como ao surgimento de novas lutas sociais (SVAMPA, 2008, p. 297, tradução nossa).
\end{abstract}

A mesma avaliação se aplica ao caso do Brasil. A reforma da previdência de 2003, já sob os auspícios do governo Lula, aliada às políticas de geração de emprego e renda com base na qualificação da mão-de-obra e flexibilização das relações trabalhistas contrapõe-se aos efeitos do programa Bolsa Família e aos aumentos reais do salário mínimo, que possuem um efeito positivo em termos de melhoria da desigualdade de renda. No entanto, é importante notar que, por princípio, o Bolsa Família não tem impacto relevante sobre o acesso à educação de qualidade, à saúde e ao emprego. A exemplo do caso argentino, o resultado final parece tênue em termos de mobilização social, consequentemente incapacitado para impedir o avanço da precarização das condições de trabalho e o desemprego estrutural - e, por sua vez, configurando-se em aumento da exploração da força de trabalho como principal resultado. Em contrapartida, os movimentos sociais, notoriamente o MST, adquirem e mantêm o status de ator político relevante contra a exploração e expropriação capitalista em curso. E isto apesar da multiplicação e aumento da extensão dos programas sociais focalizados. 


\section{tempordils}

MENDONÇA, L. J. V. P. de. POLÍTICAS ECONÔMICAS E SOCIAIS

A respeito da ingerência dos organismos financeiros internacionais, não resta dúvida de que o governo brasileiro tem tomado posições que evidenciam sua obediência às recomendações neoliberais. Isso não apenas em termos de orientação na alteração/modernização da cadeia produtiva com base principalmente na precarização das condições de trabalho, mas também em termos de disciplina fiscal e monetária, mantendo o país como um verdadeiro oásis de valorização do capital financeiro internacional. As altas taxas de juros, sob pretexto de controle da inflação, acabam por pressionar a dívida pública (emissão de títulos) e aumentar o movimento especulativo com o câmbio. O resultado final acaba por se configurar na superexploração da força de trabalho como meio de compensação do diferencial de rentabilidade entre as atividades financeiras e produtivas.

Nessa mesma linha, compreende-se o porquê do caso chileno continuar sendo emblemático para amplos setores políticos da direita latino-americana. A manutenção do sistema de aposentadoria por capitalização, apesar do enorme contingente populacional à margem de um sistema econômico e mesmo sob o governo dito de esquerda, capitaneado por $M$. Bachelet caracterizou sua atuação como assistencial. Não promoveu qualquer mudança substancial nos rumos herdados das políticas econômicas anteriores, cuja dinâmica é dada exclusivamente pelo setor exportador (agro-alimentar e mineral). A manutenção de acordos de livre comércio com os EUA, a União Européia e, posteriormente, a assinatura também de acordos com o Japão e a China falam por si sós. É clara a opção do modelo de desenvolvimento calcado nas exportações para o mercado mundial em detrimento de uma maior integração no mercado regional, via ALBA ou mesmo MERCOSUL. 


\section{temporalis}

\section{MENDONÇA, L. J. V. P. de. POLÍTICAS ECONÔMICAS E SOCIAIS}

De fato, não só no Cone Sul, mas por toda a América Latina, a internacionalização das atividades econômicas manteve-se apesar da ascensão de governos progressistas. A assinatura de acordos bilaterais com os Estados Unidos por parte do Chile, do México e demais países da América Central e Caribe são resultados desse processo $^{8}$. Também não houve qualquer iniciativa de reversão das privatizações dos anos 1990, por mais polêmicas que tenham sido. $\mathrm{Na}$ verdade, era objetivo fundamental do processo de internacionalização. Essa opção foi reforçada pela importância, ou mesmo pela prioridade dada à captação de investimentos diretos nos últimos anos:

A explosão dos IDE é um dos aspectos mais espetaculares da mundialização neoliberal. Entre 1980 e 2005 , o estoque de IDE no mundo multiplicouse por 18 e por 24 na América Latina! Em termos de estoque, a América Latina representa aproximadamente $10 \%$ do total mundial (contra apenas 5\% em 1990) (DURAND; SALUDJAN, 2008, p. 76 , tradução nossa).

Assim, os conflitos de interesses que determinam a trajetória das políticas econômicas limitam-se quase que exclusivamente àqueles oriundos da concorrência no seio da classe capitalista. As políticas de intervenção do Estado, a partir dos anos 1990 e na primeira década do século XXI, perdem seu caráter nacionalista e de mediador entre trabalhadores e capitalistas. Passam a intervir apenas para criar um lócus de acumulação, separado da realidade e do potencial da ampla maioria do povo e de acordo apenas com os

\footnotetext{
${ }^{88}$ Cabe ressaltar que tais acordos ainda não produziram todos os efeitos do livre comércio, salvo no caso do México, pois ainda dependem da aprovação do congresso dos Estados Unidos. No entanto, para efeitos da análise da posição ideológica dos mentores das políticas econômicas em vigor, constituem um marco na medida em que explicitam as diretrizes das políticas econômicas das elites latinas.
} 


\section{temporalis}

MENDONÇA, L. J. V. P. de. POLÍTICAS ECONÔMICAS E SOCIAIS

interesses do capital financeiro. No entanto, a diversidade e a importância das políticas sociais nos diversos países latinoamericanos refletem o grau de resistência política da classe trabalhadora, historicamente determinada e específica em cada país. As políticas sociais podem ser consideradas mais ou menos focalizadas e compensatórias na medida em que contribuam ou não para a construção de uma alternativa ao modelo econômico em curso. Mais do que resistência ao movimento neoliberal de desmonte das políticas sociais, do avanço de novos programas (tanto em termos de expansão dos existentes, como é o caso do Brasil, quanto de criação de novos programas, a exemplo do caso venezuelano), o que importa é como podem despontar enquanto alternativa das massas excluídas para a construção social e econômica de um modelo que não esteja baseado na expropriação contínua dos trabalhadores.

\section{REFERÊNCIAS}

BRASIL. Secretaria de Políticas Públicas de Emprego. Departamento de Qualificação. Aspectos conceituais da vulnerabilidade social: Convênio MTE/CODEFAT $n^{\circ}$ 75/2005: projeto de qualificação social para atuação de sujeitos ou grupos sociais na negociação coletiva e na gestão de políticas públicas. Brasília, 2007. Disponível em: <http://www.mte.gov.br/observatorio/sumario_-2009_TEXTOV1.pdf >.

CARVALHO, C. E. Esquerda conflitiva e política econômica: notas sobre a Argentina, Bolívia e Venezuela. In: AYERBE, L. F. (Org.). Novas lideranças políticas e alternativas de governo na América do Sul. São Paulo: UNESP, 2008. p. 183-198.

CEPAL. Panorama social da América Latina 2009: Documento informativo. Santiago de Chile, 2009. Disponível em: <http://www.eclac.org/cgi-bin/getProd.asp?xml=/publicaciones/- 


\section{temporalis}

MENDONÇA, L. J. V. P. de. POLÍTICAS ECONÔMICAS E SOCIAIS

xml/9/37839/P37839.xml\&xsl=/dds/tpl/pgf.xsl\&base=/tpl/topbottom.xsl>.

DURAND, C.; SALUDJAN, A. Les multinacionales em Amérique Latine: expansion, impact et résistances. In: GAUDICHAUD, F. (Org.). Le Volcan Latino-Américan. Paris: Textuel, 2008. p.75- 97.

FONTES, V. Marx, expropriações e capital monetário: notas para o estudo do imperialismo tardio. Fundação Lauro Campos, 2001. Disponível em: <http://www.socialismo.org.br/portal/images/arquivo/marxexpropriacapitalmonetario.pdf >. Acesso em: 3 fev. 2011.

KAY, C. Teorias estruturalistas e teoria da dependência na era da globalização neoliberal. In: SADER, E.; SANTOS, T. dos (Coord.). América Latina e os desafios da globalização. Rio de Janeiro: PUC; São Paulo: Boitempo, 2009.

MARQUES, R. M. Notas sobre a reforma previdenciária brasileira no contexto do neoliberalismo e da América Latina. Revista de Economia Política, São Paulo, v. 20, n. 1, p. 138 -148, jan./mar. 2000.

MARX, Karl. Manuscritos econômico-filosóficos. Lisboa: Lousanense, 1989. p.105.

PIZARRO, R. La vulnerabilidad social y sus desafios: una mirada desde América Latina. Santiago de Chile: CEPAL, feb. 2001. (Serie Estúdios estadísticos y prospectivos, n. 6). p.1-69.

PRADO, M. Reseña de programas sociales para la supéracíon de la pobreza en América Latina. Santiago de Chile: CEPAL, oct. 2003. (Serie Estúdios estadísticos y prospectivos, n. 20). 


\section{tempordils}

MENDONÇA, L. J. V. P. de. POLÍTICAS ECONÔMICAS E SOCIAIS

STUART, A. M. Novas lideranças na América do Sul: o caso Kirchner. In: AYERBE, L. F. (Org.). Novas lideranças políticas e alternativas de governo na América do Sul. São Paulo: UNESP, 2008. p. 15-37.

SVAMPA, M. I'Argentine des Kirchner: des continuités au double discours. In GAUDICHAUD, F. (Org.). Le volcan latino-américan. Paris: Textuel, 2008.

SVAMPA, M.; PEREYRA, S. La experiência piquetera: dimensiones y desafios de las organizaciones de desocupados em Argentina. Revista da SEP, n. 15, dez. 2004, p. 88-110.

SILVA, M. O. S. et al. A pobreza no Brasil e na Argentina: dimensão e políticas de enfrentamento. In: JORNADA INTERNACIONAL DE POLÍTICAS PÚBLICAS, 3., 2007, Maranhão. Anais... Maranhão: Programa de Pós-Graduação em Políticas Públicas da Universidade Federal do Maranhão, 2007. 